\title{
Upfront
}

\section{Uncounted: Power, inequalities and the post-2015 data revolution}

ALEX COBHAM

\begin{abstract}
People and groups go uncounted for reasons of power: those without power are further marginalized by their exclusion from statistics, while elites and criminals resist the counting of their incomes and wealth. As a result, the pattern of counting can both reflect and exacerbate existing inequalities. The global framework set by the Sustainable Development Goals will be more ambitious, in terms of both the counting and the challenging of inequalities, than anything that has gone before. This article explores the likely obstacles, and the unaddressed weaknesses in the agreed framework, and suggests a number of measures to strengthen the eventual challenge to inequalities, including by the promotion of tax justice measures.
\end{abstract}

KEYWORDS inequality; data; household surveys; SDGs; tax; uncounted

\section{Introduction}

Data: Facts and statistics collected together for reference or analysis

Revolution: A forcible overthrow of a government or social order, in favour of a new system. Oxford English Dictionary

Counting matters. As the Stiglitz et al. (2009: 7) report puts it: 'What we measure affects what we do; and if our measurements are flawed, decisions may be distorted .... [I]f our metrics of performance are flawed, so too may be the inferences that we draw'. The Commission criticizes at length the use of gross domestic product (GDP) and economic growth as the primary measures of progress, predominantly focusing on rich countries.

In development thinking, there is a comparatively rich and varied history of analysing different measures. The Millennium Development Goals (MDGs) represented the first attempt to establish a common set for all developing countries; the Sustainable Development Goals (SDGs) takes this further and identifies a universal (global) set of goals, targets and indicators, applicable from 2016 onwards.

A central feature of the SDGs is the 'data revolution'. In 2013, the UN global thematic consultation on inequalities (one of a number carried out in preparation for the SDGs) concluded that success would require, inter alia.

'... measures to strengthen the capacity and coverage of national and sub-national monitoring and evaluation, data collection and analysis. These will need to track the impact of policies,

Development (2014) 57(3-4), 320-337. doi:10.1057/dev.2015.28 


\section{Cobham: Uncounted: Power, Data and Inequalities}

legislation, budgets and programmes among those most disadvantaged and excluded; allow for truly participatory assessment of these measures; enable much more systematic disaggregation of information for equity-focused targets and indicators; and provide mechanisms for locally-led citizen monitoring and feedback on progress and performance.' (UNICEF/UNWomen, 2013: 10)

Later that year, the High Level Panel of Eminent Persons confirmed to the UN Secretary General that 'any new goals should be accompanied by an independent and rigorous monitoring system, [requiring] a data revolution for sustainable development, with an international initiative to improve the quality of statistics and information available to citizens' (UNICEF/UNWomen, 2013: 21; emphasis in original).

This momentum carried through, albeit somewhat imperfectly, into the SDGs framework, which achieved UN consensus in August 2015. This article evaluates the framework in terms of how far that 'data revolution' is likely to reach.

The term 'uncounted' is used to describe a politically motivated failure to count. This takes two main forms. First, there may be people and groups at the bottom of distributions (e.g., income) whose 'uncounting' adds another level to their marginalization, for example, where they are absent from statistics that inform policy prioritization. Second, there may be people and groups at the top of distributions who are further empowered by being able to go uncounted - not least by hiding income and wealth from taxation and regulation.

In either case, the phenomenon is not a random or arbitrary one. Being uncounted is not generally a matter of coincidence, but reflects power: the lack of it, or its excess. As such, the term 'data revolution' is most appropriate. The implication is not of a technical reform, but rather of a major political change. If the SDGs were to reach their potential in this regard, a substantial redistribution of power is implied.

It is argued here that for a range of reasons, both by design and by omission, the SDG framework is likely to go much further in tackling the phenomenon of those who are uncounted at the bottom. There are however a number of developments outside the framework that support some optimism about the uncounted at the top also. Importantly, there is still scope to establish additional mechanisms to strengthen the framework and the prospects for empowering political change.

The article is organized as follows. The first section outlines the context of development thought within which the MDGs and SDGs were adopted, highlighting the major differences in emphasis. The second section considers the implications of the SDG approach, as adopted, for those who are uncounted at the bottom: Will the framework really 'Leave No One Behind'? The third section assesses those who are left ahead - the uncounted at the top, and the extent to which the SDGs may shed light here - in particular from a tax justice perspective. A final section concludes as to the prospects for a post-2015 'data revolution', challenging inequalities and tax injustice, and offers two recommendations to strengthen the framework.

\section{Evolution of development thought: context for MDGs and SDGs}

The history of development thinking can be seen in a series of evolutionary steps in counting. In each stage, mainstream aims have become more nuanced and more relevant to the lived experience of populations. Inevitably, this greater nuance has driven better counting (i.e., better measurement of a population's lived experience). However, the causality runs in both directions because at the same time, better measurement has revealed important realities that have in turn informed different mainstream priorities.

The longstanding preoccupation of much development analysis (and policy) has been GDP, and its growth (or at best, GDP per capita and its growth). With important interventions from UNICEF's Adjustment with a Human Face (Cornia et al., 1987) and UNDP's (1990) first Human Development Report, this focus on poor countries gave way - first to a greater emphasis on non-GDP aspects of national human development, and then to a focus instead on people living in poverty. The World Bank promoted extreme income poverty as the central element, from the subsequent 1990 World Development Report (World Bank, 1990), 321 
and its 'dollar-a-day' measure was eventually adopted as the basis for the target of the first UN MDG in 2000.

Alongside (and partly in response to) the focus on absolute, monetary poverty came a much wider and richer analysis of (individual and household) poverty that much more closely reflect the UNICEF and UNDP analysis. Ruggeri-Laderchi et al. (2003) identify three main approaches.

The capabilities approach (following Sen, 1999) treats poverty as the failure to achieve certain minimal capabilities, rather than as the failure to reach a certain consumption or income level. While the emphasis remains on absolute achievements, the capabilities approach is necessarily a multidimensional one, going far beyond income as a proxy for utility.

The social exclusion approach, which had by far the most important policy role in the European Union, puts greater emphasis on relative aspects of poverty - emphasizing the ability of people to participate in a given society. From this approach tends to follow an understanding of poverty as clearly multidimensional, and significant attention to group characteristics (since these are frequently the basis for exclusion).

Finally, the participatory approach seeks to elicit views from within communities on the nature and locus of poverty. Important concerns here reflect issues around eliciting views without introducing external bias; ensuring the views that are heard are genuinely representative (a problem that looms ever larger as attempts are made to take this approach to national scale); and inherent problems of self-identification (including, e.g., the tendency to identify others as [more] poor).

Table 1 shows Ruggeri-Laderchi et al.'s (2003) comparison of these approaches with that of monetary poverty, and this is where the MDGs can reasonably be situated. Rather than specify a single definition or approach, and despite giving the World Bank's income poverty measure the headline focus, the framework as a whole set in place a breadth of goals and targets that owed much more to the capabilities approach.

In both aspects, the MDGs marked a final break from seeing development as a problem of "poor 322 countries', and focused instead on poor people.
Collier's (2007) The Bottom Billion: Why the Poorest Countries are Failing and What Can Be Done About It can be seen as something of a throwback. Its main thesis was subsequently demolished in Sumner's (2010) work on the 'new bottom billion', showing that the majority of extreme income poverty occurred - and had done for some time in middle- rather than low-income countries, reflecting within-country inequality rather than countries' absolute poverty.

The power of the latter analysis has combined with growing political attention to income and wealth inequalities in donor countries following the 2008 financial crisis (see, e.g., the unexpected prominence of Piketty, 2014). But perhaps the strongest current in development thought since the establishment of the MDGs has been that focused on group inequalities.

Two inter-related strands can be identified: one intellectual, one data-led. Of the former, much credit is due to the pioneering work on horizontal inequalities of Stewart and the Centre for Research into Inequality, Security and Ethnicity at Oxford (see, e.g. Stewart, 2002). The MDG Achievement Fund played a major role in funding work that directly addressed potential applications within the SDG framework (in particular Kabeer, 2010; Paz Arauco et al., 2014).

At the same time, the growing availability of relatively consistent survey data has allowed a range of group inequalities to be analyzed. Although the data remain far from perfect, the effect has been to demonstrate the possibility of a truly global framework with disaggregation in multiple dimensions - as reflected in calls from international NGOs such as Christian Aid (e.g. Cobham et al., 2010) and Save the Children (e.g. Espey et al., 2012; Roche et al., 2015). The Multidimensional Poverty Index (e.g. Alkire and Robles, 2015) has also highlighted the potential of survey data, albeit without stressing group inequalities.

In addition, the gender equality goal (MDG 3 of 8) has increasingly been seen as a (perhaps even 'the') success story from the MDGs. By playing an important role in making concrete a norm that was still only emerging, this in turn set the basis for the group equality norm, which runs through 
Table 1. A comparison of four approaches to poverty

\begin{tabular}{|c|c|c|c|c|}
\hline & Monetary poverty & Capability approach & Social exclusion approach & Participatory approach \\
\hline $\begin{array}{l}\text { Required or } \\
\text { minimum } \\
\text { standard } \\
\text { identified by }\end{array}$ & $\begin{array}{l}\text { Reference to 'external' } \\
\text { information (defined } \\
\text { outside the unit); central } \\
\text { element food } \\
\text { requirements }\end{array}$ & $\begin{array}{l}\text { Reference to 'lists' of } \\
\text { dimensions normally } \\
\text { assumed to be objectively } \\
\text { definable }\end{array}$ & $\begin{array}{l}\text { Reference to those } \\
\text { prevailing in society and } \\
\text { state obligations }\end{array}$ & $\begin{array}{l}\text { Local people's own } \\
\text { perceptions of well-being } \\
\text { and ill-being }\end{array}$ \\
\hline $\begin{array}{l}\text { Sensitivity to } \\
\text { social } \\
\text { institutions }\end{array}$ & $\begin{array}{l}\text { None, but assessments can } \\
\text { be broken down by group }\end{array}$ & $\begin{array}{l}\text { Emphasis on adequacy } \\
\text { rather than sufficiency } \\
\text { leaves space for (non- } \\
\text { modelled) variations }\end{array}$ & Central element & $\begin{array}{l}\text { Reflected in the way poor } \\
\text { people analyze their own } \\
\text { reality }\end{array}$ \\
\hline $\begin{array}{l}\text { Importance } \\
\text { of processes }\end{array}$ & $\begin{array}{l}\text { Not essential } \\
\text { Increasing emphasis }\end{array}$ & Not clear & $\begin{array}{l}\text { One of the main thrusts of } \\
\text { the approach }\end{array}$ & $\begin{array}{l}\text { Critical for achievement of } \\
\text { satisfactory methods }\end{array}$ \\
\hline $\begin{array}{l}\text { Problems for } \\
\text { cross-country } \\
\text { comparisons }\end{array}$ & $\begin{array}{l}\text { Comparability of surveys, } \\
\text { of price indices, of drawing } \\
\text { poverty lines }\end{array}$ & $\begin{array}{l}\text { Fewer problems if basic } \\
\text { capabilities are defined } \\
\text { externally, but adding up } \\
\text { difficulties make } \\
\text { comparisons difficult } \\
\text { with inconsistencies } \\
\text { according to adding up } \\
\text { methodology }\end{array}$ & $\begin{array}{l}\text { Lines of social exclusion } \\
\text { essentially society-specific; } \\
\text { also an adding up problem }\end{array}$ & $\begin{array}{l}\text { Cultural difference can } \\
\text { make appropriate } \\
\text { processes differ across } \\
\text { countries, results may not } \\
\text { be comparable }\end{array}$ \\
\hline $\begin{array}{l}\text { Data } \\
\text { availability }\end{array}$ & $\begin{array}{l}\text { Household surveys } \\
\text { regularly conducted; } \\
\text { omitted observations can } \\
\text { be important. Use of } \\
\text { national income data - but }\end{array}$ & $\begin{array}{l}\text { Data less regularly } \\
\text { collected, but could easily } \\
\text { be improved }\end{array}$ & $\begin{array}{l}\text { Currently have to rely on } \\
\text { data collected for other } \\
\text { purposes. If agreed on } \\
\text { basic dimensions, data }\end{array}$ & $\begin{array}{l}\text { Generally only small } \\
\text { purposive samples. Never } \\
\text { available nationally, would } \\
\text { be difficult to extend }\end{array}$ \\
\hline
\end{tabular}




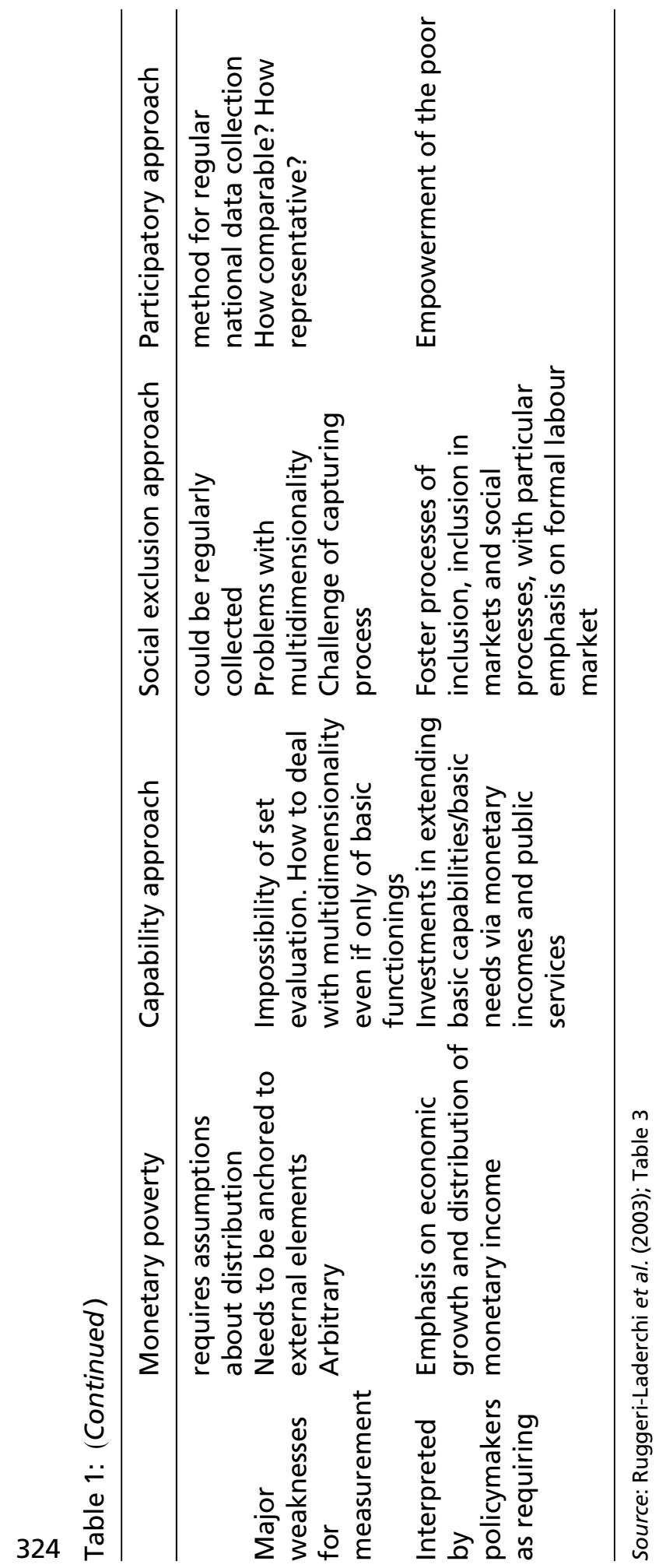

the SDGs, under the banner of 'Leave No One Behind', and is the subject of the following section.

Finally, note that both the process and the intended financing of the SDGs differ in powerful ways from that for the MDGs, and these also reflect the changing currents of development thought. The process was deliberately participatory, and established something much closer to a global conversation (albeit with inevitable issues of access and empowered engagement) than the 'few white men in a room' approach that developed the MDG framework from the original Millennium Declaration. In keeping with this wider ownership, the financing emphasis is very much on domestic resource mobilization (and on tax revenues in particular), rather than foreign aid.

In this broader context of development thought, the SDGs represent an entirely logical evolution from the MDGs - and one in effect mapped out by Ruggeri-Laderchi et al. (2003). Where the MDGs combined then-dominant monetary poverty and capabilities approaches, the SDGs add important social exclusion dynamics to the framework and in the process at least put rather greater emphasis on participatory approaches.

Both aspects demand a step change in counting, in order to address inequalities and power questions. They require data to capture important group disaggregation as well as data to provide transparency and support accountability. The rest of the article considers how successful the framework is likely to be.

\section{Uncounted at the bottom: will the SDGs really 'Leave No One Behind'?}
'As we embark on this great collective journey, we pledge that no one will be left behind. Recognizing that the dignity of the human person is fundamen- tal, we wish to see the Goals and targets met for all nations and peoples and for all segments of society. And we will endeavour to reach the furthest behind first. SDGs, finalized text for adoption' (1 August 2015: 3)

The 2013 report to the UN Secretary-General of the High Level Panel of Eminent Persons set out 'five transformative shifts', of which the first - and 


\section{Cobham: Uncounted: Power, Data and Inequalities}

the only one still referred to in terms - is to 'Leave No One Behind'. The report trod a difficult line, on the one hand emphasizing continuity from the MDGs, while on the other highlighting the extent to which a concern with social exclusion represents a significant innovation:

'The next development agenda must ensure that in the future neither income nor gender, nor ethnicity, nor disability, nor geography, will determine whether people live or die, whether a mother can give birth safely, or whether her child has a fair chance in life. We must keep faith with the promise of the MDGs and now finish the job. The MDGs aspired to halve poverty. After 2015 we should aspire to put an end to hunger and extreme poverty as well as addressing poverty in all its other forms. This is a major new commitment to everyone on the planet who feels marginalised or excluded, and to the neediest and most vulnerable people, to make sure their concerns are addressed and that they can enjoy their human rights ...

To be sure that our actions are helping not just the largest number of people, but the neediest and most vulnerable, we will need new ways of measuring success.' (High Level Panel of Eminent Persons, 2013)

A major criticism of the MDGs reflected here is that by largely ignoring identity, and targeting aggregate progress instead, the framework actually incentivized greater inequality (UNICEF, 2015).

In terms of vertical inequalities, helping those living on US\$0.01 a day is almost inevitably harder than tipping those on $\$ 0.99$ a day over the line instead. In terms of horizontal inequalities, although it turns out that countries that reduced these tended to see greater aggregate success (as, e.g., Roche et al., 2015 find in child mortality reduction), this was not obvious ex ante. Where existing inequalities reflected the balance of power in a country, and/or were not widely recognized, then a well-meaning pursuit of national progress could easily exacerbate or simply fail to address them.

The social exclusion impetus of the SDGs is intended to ensure that identity is well recognized from the outset; and that disaggregated data support accountability for addressing group inequalities.

These are the final of the 169 targets:

\section{Data, monitoring and accountability}

- 17.18. By 2020, enhance capacity-building support to developing countries, including for least developed countries and small island developing States, to increase significantly the availability of high-quality, timely and reliable data disaggregated by income, gender, age, race, ethnicity, migratory status, disability, geographic location and other characteristics relevant in national contexts.

- 17.19. By 2030, build on existing initiatives to develop measurements of progress on sustainable development that complement GDP, and support statistical capacity-building in developing countries.

Two main risks can be identified: first, that the core data necessary simply are not collected; and second, that the data are collected but characterized by such systematic weaknesses as to undermine the aims of inclusion from the outset.

Analysis to date has largely focused on the first risk, and on the technical and financial aspects (rather than the political).

Probably the most common interpretation of the 'data revolution' call has been as requiring a major increase in the coverage and frequency of household surveys - in order to establish that "neither income nor gender, nor ethnicity, nor disability, nor geography' remain determinants of major human development outcomes.

Alkire and Samman (2014: 35) compare possible data sources and conclude that "traditional in-depth survey programmes accompanied by interim surveys have the greatest potential'. Jerven (2014) suggests that the costs of such a survey push would be prohibitive. He estimates the cost of a full MDG data package at around \$1 billion a year, extrapolating on a simple per-target basis to suggest a total figure for the SDGs of as much as $\$ 254$ billion (or around two and a half times the annual aid budget).

Sandefur and Demombynes (2014), however, conclude that this is overblown. In practice, they suggest that the total of international donor assistance needed is of the order of $\$ 300$ million per year - much of which is already provided, so should not be seen as additional for the SDGs. 
Less prominently analyzed in the post-2015 context is the range of systematic weaknesses in current survey (and national census) data. Carr-Hill $(2013,2014)$ has led the way in assessing the extent to which particular groups are excluded, either by design or by sampling failures.

Household surveys by design exclude those who are not part of households, specifically: homeless populations; those in institutions (hospitals and prisons); and, highly mobile populations, including nomadic and pastoralist groups.

In addition, there is significant under-representation in practice of three further groups (all of which experience some level of insecurity or fragility): those living in informal settlements; those from households that are fragile and/or disjointed; and, those living in relatively insecure areas.

Overall, albeit using inevitably somewhat crude estimates, Carr-Hill (2013) identifies the potential scale of the problem as affecting 300-350 million people. While a randomly distributed undersampling of perhaps 5 percent of the global population might not be a grave concern, a common feature of the groups in question is the likelihood of their being overwhelmingly over-represented at the bottom of the relevant income distributions.

In a striking illustration of the implications for a single development indicator, Table 2 reproduces Carr-Hill's speculation on the impact of correcting estimates for the access to water of urban populations in sub-Saharan Africa to allow for the estimated 40 million people uncounted in informal settlements, making the extreme assumption that all are in the lowest income group and none have access to improved water sources. A similar calculation (CarrHill, 2014) suggests global improvements from 1990-2010 in water and sanitation were similar to those reported, but occurred at lower levels of achievement overall.

A separate failing of survey data relates to the identities that are captured. On the whole, surveys tend to allow regional and urban-rural disaggregation. Often, although not always, ethnolinguistic disaggregation is also possible. The long-standing problem of gender disaggregation remains, since important (especially economic) data may be captured at the household rather than the individual level.

Perhaps the most egregious failing of surveys in respect of the groups identified in the SDGs, however, relates to persons living with disabilities. Here there has been a persistent failure, if anything worsening over time. Samman and RodriguezTakeuchi (2013) address disabilities in survey data, and the somehow parallel issues of mental health and old age.

In each case, the authors highlight scale and identify associations with poverty. People over 60 make up 11 percent of the global population, and households they head are likely to have lower incomes; and that mental health disorders affect 450 million people, although the comparative lack of study and data mean that any link to poverty or poor development outcomes is less clear.

An estimated 15-20 percent of the world's population lives with some form of disability,

Table 2. Quality of water sources, urban populations of sub-Saharan Africa

\begin{tabular}{llcccccc}
\hline & Poorest quintile & Second & Middle & Fourth & Richest & All \\
\hline UN figures & Piped water & 5 & 15 & 25 & 39 & 62 & \\
& Improved source & 59 & 64 & 62 & 53 & 32 & \\
& Unimproved source & 36 & 21 & 13 & 8 & 6 & \\
& Population (millions) & 64.7 & 64.7 & 64.7 & 64.7 & 64.7 & 323.5 \\
Carr-Hill & Piped water & 0 & 0 & 18 & 45 & 67 & \\
& Improved source & 13 & 81 & 70 & 47 & 28 & \\
& Unimproved source & 87 & 19 & 12 & 8 & 5 & 363.6
\end{tabular}




\section{Cobham: Uncounted: Power, Data and Inequalities}

including those resulting from mental health issues, and the disability is considered severe for an estimated 2-4 percent of the global population. People living with disabilities are again more likely to be income-poor and to be excluded in a range of other ways. In the United Kingdom, for example, where major data challenges remain, it is estimated that women living with learning disabilities died 20 years earlier than the general population, and men with learning disabilities 13 years earlier (Heslop et al., 2013).

Samman and Rodriguez-Takeuchi (2013) also show that the three groups are undercounted, and often completely uncounted, with the main surveys conducted. There are issues in terms of coverage (e.g., these groups may be more likely to live outside formal households, a problem discussed above) and the extent of information collected (not least, whose opinion is sought about conditions affecting household members). However, the biggest issues relate to identification.

Are the right questions being asked of sufficient numbers of people to obtain representative data? Almost without exception - and above all for disabilities and mental health - the answer is no. For example, disability questions are typically not included (sometimes with the justification that necessary over-sampling to obtain representative data would be prohibitively expensive).

Where disability questions have been included, the form has been weak. For example, 'Is [NAME] physically or mentally handicapped or disabled?' Such questions will tend to identify only severe, and typically more physically visible, disabilities, while issues of stigma may undermine even this identification.

There is now fairly broad consensus although only limited practical use - of the minimum six-question approach proposed by the UN's Washington Group on Statistics, which instead puts the emphasis on self-reporting of actual capabilities:

Because of a physical, mental, or emotional health condition ...

1. Do you have difficulty seeing even if wearing glasses?
2. Do you have difficulty hearing even if using hearing aid/s or are you deaf?

3. Do you have difficulty walking or climbing stairs?

4. Do you have difficulty remembering or concentrating?

5. Do you have difficulty (with self-care such as) washing all over or dressing?

6. Do you have difficulty communicating (for example, understanding or being understood by others)?

Question response categories: No, Some, A lot, and Unable.

Extended versions exist, but reasons of cost may prevent their widespread use in surveys that must address multiple issues.

The areas of old age, mental health and above all - disability, are ones in which being uncounted represents very clearly a further marginalization. Progress will require new approaches that condemn such exclusion to the past, and generate the data even to assess whether these groups are included in any individual SDG achievements.

Survey data are of course not the only options. Outlining elements of a solution to the systematic omissions he identifies, Carr-Hill (2013) highlights the importance of accurate census data, both as a central element of national statistics in their own right and as the basis to assess and possibly to reweight survey findings.

Census data in turn rests on two further aspects of the 'Leave No One Behind' agenda: vital registration and legal identity. Target 16.9 of the SDGs reads:

- By 2030, provide legal identity for all, including birth registration

Dunning et al. (2014) note three reasons: that recognized identity supports the establishment of (at least notional) rights vis-à-vis a state; that it facilitates (practical) access to state services; and third, to support better data. Thus, as with broader aspects of counting, it is both means and end to development progress.

Once again, the uncounted are not an arbitrary group: "it is no accident that those lacking birth registration and legal identity are typically the most vulnerable people in the poorest countries' 
(Dunning et al., 2014: 3). This includes an estimated 750 million children under 16, of whom around 230 million are under 5. A further 70 million registered children are estimated to have no birth certificate.

Dunning et al. (2014) argue for two distinct targets, reflecting the different roles of birth registration and legal identity, and the feasibility of progress in each area:

- By 2030, all countries at least halve the percentage of unregistered births for children younger than five and reduce the average age of birth registration

- By 2030, ensure that all individuals have welldefined and recognized legal identity by the time they become adult (15-18)

A further set of concerns relate to the linkages between legal identity and citizenship (Bloom, 2015). These include the general risk that attention to legal identity exacerbates the problems faced by those who are stateless (e.g., that they may receive an identity that confers illegal status, in effect; or that the SDGs' emphasis on accountability to citizens may exclude them more comprehensively even than presently). The need to ensure rights regardless of legal identity or citizenship is not made generally explicit (although migrants are explicitly included in some targets).

Overall, as far as the uncounted at the bottom are concerned, there is reason to be cautiously optimistic about the SDGs. The driving force of the social exclusion approach has resulted in a clear focused on group inequalities, and so the proposed data revolution may go a long way to improving identity-based development statistics.

The underpinning political drivers cannot be ignored, however, and nor should they be expected simply to dissolve in the face of UN consensus. There is no coincidence in the fact that so many of the groups about whom data is now sought, but currently unavailable, have been unable to exert the effective political demand to be counted.

This may reflect a widespread lack of understanding or concern, for example, as is likely to be the case worldwide for persons living with disabil328 ities. It may reflect embedded political dynamics, for example, such as that facing indigenous populations in countries from Australia to Canada that result in what the UN Special Rapporteur refers to as 'nearly universal disadvantageous social and economic conditions' (OHCHR, 2014); or something more targeted such as the apparently deliberate marginalization of multiple regions and ethnolinguistic groups in Sudan (Cobham, 2005). ${ }^{1}$

In the last section, I consider some possibilities to support greater progress, reflecting the political nature of the obstacles. Before doing that, it is essential to explore the role of the SDGs in respect of uncounted phenomenon related to the top of the distribution.

\section{Uncounted at the top: hidden inequalities and tax justice}

At the other end of the distribution are phenomena that go uncounted because of an excess of power: tax abuses of individuals and companies; the financial secrecy provided by jurisdictions including some of the richest that undermine tax and the rule of law in others including the poorest; and the hidden criminality of private and public sector corruption. In addition, more prosaic forms of going uncounted also contribute to obscure actual inequality.

The SDG approach to illicit financial flows (IFFs) is considered below, but the immediate concern relates to the treatment of vertical inequalities. The most relevant goals and targets are as follows.

\section{Goal 10: Reduce inequality within and among countries}

- 10.1. By 2030, progressively achieve and sustain income growth of the bottom 40 per cent of the population at a rate higher than the national average

- 10.2. By 2030, empower and promote the social, economic and political inclusion of all, irrespective of age, sex, disability, race, ethnicity, origin, religion or economic or other status

- ...

- 10.4. Adopt policies, especially fiscal, wage and social protection policies, and progressively achieve greater equality 


\section{Cobham: Uncounted: Power, Data and Inequalities}

Fully capturing the distribution at the top is necessary to assess the extent to which growth is inclusive, and to ensure that fiscal policies progressively achieve greater equality.

Cobham et al. (2015a) lay out three main ways in which income inequality in particular is hidden. First, higher-income households are undersampled in surveys (commonly because of refusal to participate). Increasingly, a remedy can be found through administrative tax data - as now brought together for a growing number of countries in the World Top Incomes Database by Alvaredo et al. (2015). Using such tax data appears to add in the order of 3-6 percentage points to the resulting Gini coefficient, for national (e.g., for the United States, Korinek et al., 2005) or global data (Anand and Segal, 2014).

Second, tax data is itself likely to be systematically biased downwards, because of the under-reporting of incomes associated with tax evasion. Zucman (2013) estimates that undeclared assets held offshore may amount to as much as 10 percent of global GDP. Forthcoming analysis (Cobham et al., 2015b) using IFF (rather than stock) estimates suggests that the resulting adjustment to national Gini coefficients for undeclared incomes may be of the same order as that found by allowing for declared incomes via administrative tax data.

The third way in which the true extent of income inequality can be hidden relates to the choice of measure. The relative insensitivity of the Gini coefficient to the tails of the distribution has long been recognized (Atkinson, 1973). Cobham and Sumner (2013a, b) demonstrate that the Gini is also relatively insensitive at higher levels of inequality.

In addition, these papers provide evidence that such is the relative stability (across countries and over time) of the income share of deciles 5-9 that despite its oversensitivity here that a regression of the Gini on the bottom 40 percent and top 10 percent income shares alone produces near-perfect fit. That same stability supports Palma's (2006, 2011) findings, and the proposal of Cobham and Sumner $(2013 \mathrm{a}, \mathrm{b})$ for an alternative inequality measure, the Palma ratio: the ratio of national income shares of the top 10 percent to the bottom 40 percent, since this is where most income inequality actually occurs.
Per Atkinson (1973), no single measure of inequality is without subjective implications; the best we can do is to be aware of that which we use. Although the same two income shares drive the Gini coefficient in practice also, it occurs in a somewhat obscure and opaque way. In the Palma ratio, by contrast, it is direct and transparent.

The subtitle of Palma's (2011) paper is 'The share of the rich is what it's all about'. What is disappointing about the income inequality measure in the SDGs is that it obscures the share of the rich almost completely.

As discussed above, the centrality of social exclusion as the development approach behind the SDG framework results in great emphasis on group inequalities, and in particular on marginalized groups. Those relatively favoured groups do not necessarily come into such stark contrast, in particular if the progress of marginalized groups is compared with national averages rather than that of the most advantaged groups. This logic reaches a nadir in the 'income inequality' target.

The relationship between the bottom 40 percent, deciles 5-9 and the top 10 percent shares of national income is such that, in general, the target of higher income growth for the bottom 40 percent than for the mean is likely to be associated with reductions in the Palma or Gini - but it is unclear why such a circular and complex route is preferred to, for example, the Doyle and Stiglitz (2014) proposal of targeting a Palma ratio of 1 , in each country, by 2030.

The uncounted nature of some part of top-end incomes introduces no less important a bias in the SDG target than it would in a Palma target, only that it is somewhat hidden.

The choice of SDG target was influenced by the World Bank's 'shared prosperity' measure: to foster the per capita income growth of the poorest 40 percent of people in each country. This was added in 2013 as a second target for the institution (alongside reducing extreme income poverty to 3 percent of the world population). Chief economist Basu (2013) defended the measure thus:

'There has been some criticism that the focus on the growth rate of the per capita income of the poorest 40 percent ignores inequality. This criticism is 
misplaced. Since each nation already tracks the growth rate of the per capita income of its entire population and these data are widely available, as soon as we see the growth rate of the bottom 40 percent next to this figure, it will be immediately obvious as to whether the poorest 40 percent is falling off from the rest or catching up. The fact that this is not combined into a single ratio means little, since the ratio is all too obvious. Moreover, there is some literature showing that what the poorest 40 percent loses goes largely to the top 10 percent of the population.' (Palma, 2011; Green, 2012)

It was perhaps inevitable that the World Bank's measure would not be taken directly into the SDGs, when its defenders begin by recognizing that only as a ratio can it speak to inequality. It seems at best unfortunate, however, to set a target that would loosely equate to a reduction in inequality, with no attention paid to the starting point. Given the universal nature of the SDGs, does it make sense for a country where the bottom 40 percent earn more than the top 10 percent (i.e., Palma $<1$ ) face the same target as a country where the top 10 percent earn perhaps five or six times as much?

Ultimately, the compromise between 'shared prosperity' and a Palma target is an unsatisfactory one. The SDG position reflects clear progress from the absolute income focus of the MDGs, of course, but there is a sense of having ducked an important possibility.

Returning to IFFs, a somewhat similar conclusion may be reached. In theory, MDG 8 (Develop a global partnership for development), and target $8 \mathrm{~A}$ in particular, may be relevant: 'Develop further an open, rule-based, predictable, non-discriminatory trading and financial system'.

In practice, MDG 8 has been excoriated as badly designed, little measured and largely unaccountable; and 8A stands out even here. Not only is the target not SMART (arguably, it meets none of the criteria at all: certainly it is neither specific nor measurable); there is also no single indicator in the framework that relates.

Overall, the MDGs focused strongly on aid and had no space for domestic taxation; and included no references beyond the vague wording of $8 \mathrm{~A}$ to the transparent or fair operation of international finance and trade.
The SDGs have responded in two important ways. First, in line with the aim of national ownership (and the emphasis on participation), there is a clear focus on domestic resource mobilization rather than aid.

- 17.1. Strengthen domestic resource mobilization, including through international support to developing countries, to improve domestic capacity for tax and other revenue collection

Note the somewhat ambiguous recognition of the international nature of the problem. Some (non-aid donor) countries had apparently pushed for clarity over international responsibility, for example, in respect of full inclusion of developing countries in the exchange of tax information; some (donor) countries rejected this, allowing instead the language on support that could be interpreted as technical assistance in-country alone.

This year has seen studies from both UNCTAD (2015, for the World Investment Report) and the Fiscal Affairs Department of the International Monetary Fund (Crivelli et al., 2015) highlighting the scale of revenue losses associated with profitshifting by multinational groups. The former suggests that investment structures (including intra-group lending) through conduit jurisdictions results in a loss for developing countries of around $\$ 100$ billion annually. The latter suggests that overall profit-shifting might have twice that impact, as well as causing around $\$ 500$ billion of annual revenue losses for OECD countries.

The fact that such estimates (based variously on statistics on tax revenues, FDI income and corporate tax rates) are currently the best guide for policy reflects a further aspect of uncounted. Current corporate reporting rules do not provide for country-by-country information on the economic activities and tax paid by multinational groups; and without this, neither the multinationals nor national tax authorities can be effectively held accountable for their approaches.

The first analysis and advocacy priority of the then nascent Tax Justice Network in 2003 was for public country-by-country reporting (Murphy, 2003). Ten years later, with increasing pressure from media revelations about corporate tax abuse such as 'LuxLeaks', the G8 and G20 groups of 


\section{Cobham: Uncounted: Power, Data and Inequalities}

countries called for the OECD to develop just such a standard, which it has now done (OECD, 2014).

At present, however, the information generated (potentially by every multinational group) will only be supplied to individual tax authorities - so while some abuses may become visible and be addressed, there will be no greater public accountability of either multinationals or tax authorities.

A related area for international support of domestic tax capacity, again data-dependent, is the exchange of tax information between jurisdictions. This was the second of the Tax Justice Network's original priorities, and again was adopted by the G8 and G20 some ten years later, and the OECD mandated to deliver. The automatic provision of information is seen as a powerful mechanism to minimize the hiding of taxable wealth and incomes in other jurisdictions including tax havens.

Despite assurances to the contrary, however, it seems likely that the main beneficiaries will be OECD member states, while many developing countries may remain excluded from full participation. In addition, there are currently no plans in place to ensure consistent partially aggregated is published on the scale of bilateral holdings - so once again, the scope for accountability of tax authorities, or indeed of jurisdictions for their contribution to international financial transparency, or opacity.

The lack of indicators in the SDGs, or indeed in the Financing for Development document, suggests again a missed opportunity to support domestic tax capacity - this time by improving the counting of elites' offshore incomes. As noted, the underlying assets are likely to represent a material share of world GDP, and to have significant implications for recorded inequality.

The second and closely related area in which the SDGs include a target, again reflecting the emergence of tax justice ideas onto the international policy agenda since the mid-2000s, is on and IFFs:

- 16.4. By 2030, significantly reduce illicit financial and arms flows, strengthen the recovery and return of stolen assets, and combat all forms of organized crime

The Financing for Development outcome document adds further emphasis and some specificity, including on international cooperation that to some extent responds to the ambiguity in SDG 17.1 noted above:

'We will redouble efforts to substantially reduce illicit financial flows by 2030, with a view to eventually eliminating them, including by combating tax evasion and corruption through strengthened national regulation and increased international cooperation.' (UN, 2015: 8)

The dictionary definition of illicit is 'forbidden by law, rules or custom'; that is, it goes beyond narrow illegality. The consistent feature of IFFs - those that are certainly illegal, such as cross-border moneylaundering and tax evasion, and that those may be legal but are socially unacceptable such as the most egregious tax avoidance (or unproven evasion) of some multinational companies - is the use of financial secrecy to prevent public visibility.

Table 3 provides a broad (although inevitably not comprehensive) typology of illicit flows. Four main types can be identified: tax abuse (individual and corporate); market or regulatory abuse (e.g., hiding monopoly dominance); abuse of power (e.g., bribery of those in public office, or the hiding of political conflicts of interest, or the theft of state assets); and, laundering of the proceeds of crime.

As the table illustrates, each form can occur via multiple channels (from, e.g., mispricing of trade to the use of anonymous shell companies); and each channel can be used for more than one form of illicit flow. As a result, precise estimates are difficult. The leading estimates of total IFFs come from Global Financial Integrity (Kar and Spanjers, 2014), and combine a 'hot money' component reflecting capital account anomalies with a 'misinvoicing' component reflecting trade anomalies.

While there are criticisms of each, and alternatives in specific areas where more detailed trade data, for example, has been available (Pak and Zdanowicz, 2000), Global Financial Integrity has long set the challenge to international institutions to do better. As yet, none have attempted it. One major benefit of the SDG target then - vague and currently unmeasured as it is - is that it may finally prompt action, perhaps from the World Bank or the International Monetary Fund (IMF) or ideally a broader collaboration including NGO 
Table 3. A typology of IFFs and immediate impacts

\begin{tabular}{|c|c|c|c|c|c|}
\hline Flow & Manipulation & Illicit motivation & $\begin{array}{l}\text { IFF } \\
\text { type }\end{array}$ & $\begin{array}{l}\text { Impact on } \\
\text { state funds }\end{array}$ & $\begin{array}{l}\text { Impact on state } \\
\text { effectiveness }\end{array}$ \\
\hline \multirow[t]{5}{*}{ Exports } & Over-pricing & Exploit subsidy regime & 2 & $\downarrow$ & $\downarrow$ \\
\hline & & (Re)patriate undeclared capital & 1 & $\downarrow$ & $\downarrow$ \\
\hline & Under-pricing & Shift undeclared (licit) income/profit & 2 & $\downarrow$ & $\downarrow$ \\
\hline & & Shift criminal proceeds out & 4 & $\downarrow$ & $\downarrow$ \\
\hline & & $\begin{array}{l}\text { Evade capital controls (including on } \\
\text { profit repatriation) }\end{array}$ & 1 & & $\downarrow$ \\
\hline \multirow[t]{6}{*}{ Imports } & Under-pricing & Evade tariffs & 2 & $\downarrow$ & $\downarrow$ \\
\hline & & (Re)patriate undeclared capital & 1 & $?$ & $\downarrow$ \\
\hline & Over-pricing & Shift undeclared (licit) income/profit & 2 & $\downarrow$ & $\downarrow$ \\
\hline & & Shift criminal proceeds out & 4 & $?$ & $\downarrow$ \\
\hline & & $\begin{array}{l}\text { Evade capital controls (including on } \\
\text { profit repatriation) }\end{array}$ & 1 & $\downarrow$ & $\downarrow$ \\
\hline & & Shift undeclared (licit) income/profit & 2 & $\downarrow$ & $\downarrow$ \\
\hline \multirow{6}{*}{$\begin{array}{l}\text { Inward } \\
\text { investment }\end{array}$} & Under-pricing & Shift undeclared (licit) income/profit & 2 & $\downarrow$ & $\downarrow$ \\
\hline & & Shift criminal proceeds out & 4 & $?$ & $\downarrow$ \\
\hline & & $\begin{array}{l}\text { Evade capital controls (including on } \\
\text { profit repatriation) }\end{array}$ & 1 & $\downarrow$ & $\downarrow$ \\
\hline & Over-pricing & (Re)patriate undeclared capital & 1 & $?$ & $\downarrow$ \\
\hline & Anonymity & Hide market dominance & 1 & & $\downarrow$ \\
\hline & Anonymity & Hide political involvement & 3 & & $\downarrow$ \\
\hline \multirow[t]{4}{*}{$\begin{array}{l}\text { Outward } \\
\text { investment }\end{array}$} & Under-pricing & $\begin{array}{l}\text { Evade capital controls (including on } \\
\text { profit repatriation) }\end{array}$ & 1 & & $\downarrow$ \\
\hline & Over-pricing & Shift undeclared (licit) income/profit & 2 & $?$ & $\downarrow$ \\
\hline & & Shift criminal proceeds out & 4 & $\downarrow$ & $\downarrow$ \\
\hline & Anonymity & Hide political involvement & 3 & & $\downarrow$ \\
\hline Public lending & $\begin{array}{l}\text { (If no expectation of repayment, } \\
\text { or if under-priced) }\end{array}$ & $\begin{array}{l}\text { Public asset theft (illegitimate } \\
\text { allocation of state funds) }\end{array}$ & 3 & $\downarrow$ & \\
\hline Public borrowing & $\begin{array}{l}\text { (If state illegitimate, or if over- } \\
\text { priced) }\end{array}$ & $\begin{array}{l}\text { Public asset theft (illegitimate } \\
\text { creation of state liabilities) }\end{array}$ & 3 & $\downarrow$ & \\
\hline \multirow{2}{*}{$\begin{array}{l}\text { Related party } \\
\text { lending }\end{array}$} & Under-priced & Shift undeclared (licit) income/profit & 2 & $\downarrow$ & \\
\hline & Over-priced & Shift undeclared (licit) income/profit & 2 & $\downarrow$ & \\
\hline
\end{tabular}




\section{Cobham: Uncounted: Power, Data and Inequalities}

expertise, to establish a methodology around which consensus can be formed. Ideally, such an approach would come closer to the breadth of IFF in Table 3, and the work cited by UNCTAD and IMF researchers on multinational tax losses could well form a part.

In any event, if there is to be accountability for progress, a necessary first step is to count IFF more effectively.

\section{Conclusions and policy recommendations}

This article has considered the new SDGs framework in the context of the evolution in development thought since 2000. The greater emphasis on social exclusion and participatory approaches to poverty has been seen to underpin the framework's attention to power and to inequalities, which represent important shifts from the focus on absolute income poverty and basic capabilities that characterized the MDGs.

If this shift is to gain traction in policy terms, and to drive meaningful rebalancing of political power as is implied, then the much-heralded data revolution will truly be required. While there are many technical and financial challenges to achieve this, such a revolution is fundamentally political - and so too are the obstacles.

The thesis of 'uncounted' put forward here asserts that marginalized groups are often further excluded by their absence from statistics used for policy or in public debate, while elites may be further empowered by their lack of visibility. In both cases, technical fixes alone will not address the political reasons for the inequalities - but genuine progress on counting can be a powerful step towards addressing the wider inequalities.

Two proposals are put forward, with the common aim of strengthening the political accountability of the counting that the framework requires. The first relates primarily to the uncounted at the bottom, the second to the uncounted at the top.

\section{Quis numerabit ipsos numeratores?}

Who will count those who themselves are counting? A major risk is that states and/or elites will 333 
either actively suppress the collation or publication of data on uncomfortable inequalities (note 1), or more through inertia simply fail to prioritize sufficiently the counting of those who are in fact most marginalized (consider, e.g., the failures globally in relation to persons with learning disabilities, and indigenous populations; or the effective absence of elites from much income distribution data).

At a minimum, reporting structures should be put in place so that the presence or absence of reporting, in relation to each inequality type relevant to each target, is itself reported. This would facilitate the comparison and ranking of the extent of uncounted phenomena, by issue; by inequality type and/or group; and by country and region. Is health better counted than income poverty? Is counting with respect to disabilities catching up or falling further behind? Which countries are leading, and which trailing, and why? Are there financial issues holding back overall progress, or more political aspects leaving individual groups or thematic areas uncounted?

Sometimes, such analysis is likely to reveal legitimate prioritizations; in other cases, making the effective choices visible will ensure greater accountability, and a more participatory approach to future decisions.

Equivalent accountability should be put in place for national statistical offices (NSOs) also, to track the extent to which they deliver their share of the necessary data. Here the importance is as much to support the independence of NSOs from domestic political pressure, as to hold them accountable themselves. To this end, the global framework might usefully be augmented by the addition of annual indicators for each country of the de facto and de jure independence of NSOs, as are often constructed for central bank independence, for example.

\section{Leave no one ahead, uncounted}

Even with the convoluted income inequality target 10.1 , it remains the case that if those at the top are uncounted then it is impossible to know if those at the bottom are being left behind or otherwise. While there may be more political discomfort to a 334 focus on top incomes, or other development outcomes - and perhaps exactly because of that discomfort - it is important that these groups do not remain uncounted, if the SDGs are to deliver their promise.

A specific aspect of uncounted at the top relates to the inclusion or otherwise of data on offshore assets and incomes to lower-income countries, and the publication or otherwise of partial aggregates for accountability of both taxpayers and tax authorities, along with the country-by-country reporting of multinationals for exactly the same reasons.

Much like the non-aid commitments of donor countries in MDG 8, the G8 has yet to deliver on its promises of 2013 to ensure full inclusion of developing countries in tax information exchange. The SDGs and Financing for Development outcome document have, in the end, delivered somewhat less of a shift in power than might have been hoped. Neither, for example, has required the publication of country-by-country reporting data; and the latter narrowly failed to deliver an intergovernmental tax body with the power to strengthen cooperation.

Nevertheless, existing commitments in the two documents provide the basis for annual tracking of the following:

- For each country and jurisdiction, on what proportion of foreign-owned assets and to the states of what proportion of the world's population, are they providing tax information bilaterally to others?

- For each country and jurisdiction, from which countries and jurisdictions are they receiving tax information bilaterally?

- For each country and jurisdiction receiving information, what proportion and volume of revealed assets were already declared by the taxpayer, and what resolution has reached each year in respect of the remainder?

- For each country and jurisdiction, for multinationals making up what proportion of the declared multinational tax base is country-bycountry reporting publicly available?

- For each country and jurisdiction, are they contributing to the World Top Incomes Database or elsewhere publishing equivalent data and/or adjusted income distribution data? 


\section{Cobham: Uncounted: Power, Data and Inequalities}

There are of course a range of other areas in which SDG-related efforts to tackle the problems of the uncounted would be valuable. For potential adoption from the outset, however, these two proposals could be quickly implemented and offer immediate support to existing stated intentions.
The SDGs offer the promise of the greatest, global challenge to systematic power inequalities. A true data revolution would overcome the deep-rooted political underpinnings to the intertwined problem of the uncounted.

\section{Acknowledgements}

The author is grateful for comments from participants and discussants at seminars and conferences at Birmingham, Columbia, Heriot-Watt, NYU Law School and at the Pan-African Conference on Inequalities in the Context of Structural Transformation in Accra.

\section{Note}

1 The paper shows the pattern by combining regionally disaggregated data on health and education outcomes, with equivalently disaggregated fiscal data published by the IMF in the early 2000s. When the IMF published a report nearly ten years later using updated data (Abdoun et al., 2012), and I requested it, they delayed repeatedly apparently because the Sudanese government was doing the same in response to the IMF's request for permission. Ultimately, the data was not made available to me - or, presumably, to any Sudanese or other citizen with an interesting in exploring these questions.

\section{References}

Abdoun, Ramdane, Jemma Dridi, Valentina Flamini and Kerstin Gerling (2012) Sudan: Selected issues. Washington DC: International Monetary Fund.

Alkire, Sabina and Gisela Robles (2015) Multidimensional Poverty Index - 2015: Brief methodological note and results. Oxford: Oxford Poverty and Human Development Initiative.

Alkire, Sabina and Emma Samman (2014) 'Mobilising the Household Data Required to Progress Toward the SDGs', OPHI Working Paper 72, Oxford: Oxford Poverty and Human Development Initiative.

Alvaredo, Facundo, Anthony B. Atkinson, Thomas Piketty and Emmanuel Saez (2015) The World Top Incomes Database, http://topincomes.g-mond.parisschoolofeconomics.eu, accessed 6 August 2015.

Anand, Sudhir and Paul Segal (2014) 'The Global Distribution of Income', Oxford Department of Economics Discussion Paper 714, Oxford: Oxford University.

Atkinson, Anthony B. (1973) 'On the measurement of inequality', reprinted from Journal of Economic Theory (1970), with non-mathematical summary: 46-68, in A. Atkinson (ed.) Wealth, Income and Inequality, Harmondsworth: Penguin.

Basu, Kaushik (2013) 'Shared Prosperity and the Mitigation of Poverty in Practice and in Precept', World Bank Policy Research Working Paper 6700, Washington DC: World Bank.

Bloom, Tendayi (2015) “"Transforming Our World” - How can we Make Sure no One is Left Behind?' European Network on Statelessness, http://www.statelessness.eu/blog/transforming-our-world\%E2\%80\%99-how-can-wemake-sure-no-one-left-behind, accessed 5 August 2015.

Carr-Hill, Roy (2013) 'Missing Millions and Measuring Development Progress', World Development 46: 30-44.

Carr-Hill, Roy (2014) 'Measuring Development Progress in Africa: The denominator problem', Canadian Journal of Development Studies 35(1): 136-154.

Cobham, Alex (2005) 'Causes of Conflict in Sudan: Testing the black book', European Journal of Development Research 17: 462-480.

Cobham, Alex (2014) 'The Impact of Illicit Financial Flows on Peace and Security in Africa', Tana Forum 2014 Background Paper, Bahir Dar: Tana High-Level Forum on Security in Africa.

Cobham, Alex and Andrew Hogg Multiple Christian Aid Contributors (2010) We're All in This Together. London: Christian Aid.

Cobham, Alex, Luke Schlogl and Andy Sumner (2015a) 'Inequality and the Tails: The Palma proposition and ratio revisited', DESA Working Paper 143, New York: UN Department of Economic and Social Affairs.

Cobham, Alex, W. Davis, G. Ibrahim and Andy Sumner (2015b) 'Hidden Inequality: How much difference would adjustment for illicit financial flows make to national inequality?', Paper Prepared for African Economic Conference 2015. 


\section{Development 57(3-4): Upfront}

Cobham, Alex and Andy Sumner (2013a) 'Putting the Gini Back in the Bottle? "The Palma" as a Policy-Relevant Measure of Inequality', mimeograph, London: King's College London.

Cobham, Alex and Andy Sumner (2013b) 'Is it All About the Tails? The Palma Measure of Income Inequality', CGD Working Paper 343, Washington DC: Center for Global Development.

Collier, Paul (2007) The Bottom Billion: Why the poorest countries are failing and what can be done about it. Oxford: Oxford University Press.

Cornia, Giovanni Andrea, Richard Jolly and Frances Stewart (1987) Adjustment with a Human Face. Oxford: Clarendon Press.

Crivelli, Ernesto, Ruud A. de Mooij and Michael Keen (2015) 'Base Erosion, Profit Shifting and Developing Countries', IMF Working Paper 118, Washington DC: International Monetary Fund.

Doyle, Michael W. and Joseph E. Stiglitz (2014) 'Eliminating Extreme Inequality: A sustainable development goal, 2015-2030', Ethics and International Affairs 28(10): 1-7.

Dunning, Casey, Alan Gelb and Sneha Raghavan (2014) 'Birth Registration, Legal Identity, and the Post-2015 Agenda', CGD Policy Paper 46, Washington DC: Center for Global Development.

Espey, Jessica, Alison Holder, Nuria Molina and Alex Cobham (2012) Born Equal: How reducing inequality could give our children a better future. London: Save the Children.

Green, Duncan (2012) From Poverty to Power: How active citizens and effective states can change the world. Oxford: OXFAM International, (cited in Basu, 2013).

Heslop, Pauline, Peter Blair, Peter Fleming, Matt Hoghton, Anna Marriott and Lesley Russ (2013) Final Report of the Confidential Inquiry into Premature Deaths of People with Learning Disabilities (CIPOLD). Bristol: Bristol University.

High Level Panel of Eminent Persons (2013) A New Global Partnership: Eradicate poverty and transform economies through sustainable development. New York: United Nations.

Jerven, Morten (2014) 'Benefits and Costs of the Data for Development Targets for the Post-2015 Development Agenda', Post-2015 Consensus Assessment, Copenhagen: Copenhagen Consensus Center.

Kabeer, Naila (2010) Can the MDGs Provide a Pathway to Social Justice? The Challenge of Intersecting Inequalities. Sussex: IDS/MDG Achievement Fund.

Kar, Dev and Joseph Spanjers (2014) Illicit Financial Flows from Developing Countries: 2003-2012. Washington DC: Global Financial Integrity.

Korinek, Anton, Johan A. Mistiaen and Martin Ravallion (2005) 'Survey Nonresponse and the Distribution of Income', World Bank Working Paper 3543, Washington DC: World Bank.

Murphy, Richard (2003) A Proposed International Accounting Standard: Reporting turnover and tax by location. Basildon: Association of Accountancy and Business Affairs.

OECD (2014) 'Guidance on Transfer Pricing Documentation and Country-by-Country Reporting', OECD/G20 Base Erosion and Profit Shifting Project Action 13: 2014 deliverable, Paris: Organisation for Economic Cooperation and Development.

OHCHR (2014) Report of the Special Rapporteur on the rights of indigenous peoples, Victoria Tauli Corpuz, A/HRC/ 27/52, Geneva: Office of the High Commissioner for Human Rights.

Palma, José Gabriel (2006) 'Globalizing Inequality: “Centrifugal” and "centripetal” forces at work', DESA Working Paper 35, New York: UN Department of Economic and Social Affairs.

Palma, José Gabriel (2011) 'Homogeneous Middles vs. Heterogeneous Tails, and the End of the 'Inverted-U': The share of the rich is what it's all about', Development and Change 42(1): 87-153.

Pak, Simon J. and John S. Zdanowicz (2000) 'Pilot Study for US Congress - Analysis of the U.S. merchandise trade data base: The detection of abnormal transfer pricing and the collection of under-payments of U.S. income taxes' (not public).

Paz Arauco, Veronica, Haris Gazdar, Paula Hevia-Pacheco, Naila Kabeer, Amanda Lenhardt, Syeda Quratulain Masood, Haider Naqvi, Nandini Nayak, Andrew Norton, Nidhi Sadana Sabharwal, Elisa Scalise, Andrew Shepherd, Deepak Thapa, Sukhadeo Thorat, D. Hien Tran, Leandro Vergara-Camus, Tassew Woldehanna and Chiara Mariotti (2014) Strengthening Social Justice to Address Intersecting Inequalities Post-2015. London: ODI/Spanish Development Cooperation/MDG Achievement Fund.

Piketty, Thomas (2014) Capital in the Twenty-First Century. Boston, MA: Harvard University Press.

Roche, José-Manuel, Lisa Wise, Dimitri Gugushvili and Luisa Hanna (2015) The Lottery of Birth: Giving all children an equal chance to survive. London: Save the Children.

Ruggeri-Laderchi, Caterina, Ruhi Saith and Frances Stewart (2003) 'Does it Matter that we do not Agree on the Definition of Poverty? A Comparison of Four Approaches', Oxford Development Studies 31(3): 243-274.

Sandefur, Justin and Gabriel Demombynes (2014) 'Costing a Data Revolution', CGD Working Paper 383, Washington DC: Center for Global Development.

Samman, Emma and Laura K. Rodriguez-Takeuchi (2013) 'Old age, Disability and Mental Health: Data issues for a post-2015 framework', ODI Background Note, London: Overseas Development Institute. 


\section{Cobham: Uncounted: Power, Data and Inequalities}

Sen, Amartya (1999) Development as Freedom. Oxford: Oxford University Press.

Stewart, Frances (2002) 'Horizontal Inequalities: A neglected dimension of development', Queen Elizabeth House Working Paper 81, Oxford: Department of International Development.

Stiglitz, Joseph E., Amartya Sen and Jean-Paul Fitoussi (2009) Report of the Commission on the Measurement of Economic Performance and Social Progress. Paris: Commission on the Measurement of Economic Performance and Social Progress.

Sumner, Andy (2010) 'Global Poverty and the New Bottom Billion: Three-quarters of the world's poor live in middleincome countries', IDS Working Paper 349, Brighton: Institute of Development Studies.

UN (2015) Outcome document of the Third International Conference on Financing for Development: Addis Ababa Action Agenda, A/CONF.227/L.1, New York: United Nations.

UNCTAD (2015) 'World Investment Report 2015', Geneva: United Nations Conference on Trade and Development.

UNDP (1990) Human Development Report. New York: United Nations Development Programme.

UNICEF (2015) 'Beyond Averages: Learning from the MDGs' in Kai Bucher, Tara Dooley, Céline Little, Claudia Gonzalez Romo, Zahra Sethna, Jordan Tamagni (eds.) Progress for Children 11. New York: United Nations Children's Fund.

UNICEF/UNWomen (2013) Addressing Inequalities: Synthesis report of global thematic consultation on the post-2015 development agenda. New York: United Nations.

World Bank (1990) World Development Report 1990: Poverty. Washington DC: World Bank.

Zucman, Gabriel (2013) 'The Missing Wealth of Nations: Are Europe and the U.S. net debtors or net creditors?', Quarterly Journal of Economics 128(3): 1321-1364. 